\title{
Dual-Directional Immunomodulatory Effects of Corbrin Capsule on Autoimmune Thyroid Diseases
}

\author{
Tianyi He, ${ }^{1}$ Ruxing Zhao, ${ }^{1}$ Yiran Lu, ${ }^{1}$ Wenjuan Li, ${ }^{1}$ Xinguo Hou, ${ }^{1}$ Yu Sun, \\ Ming Dong, ${ }^{1}$ and Li Chen ${ }^{1,2}$ \\ ${ }^{1}$ Department of Endocrinology, Qilu Hospital, Shandong University, Jinan, Shandong 250012, China \\ ${ }^{2}$ Institute of Endocrinology and Metabolism, Shandong University, Jinan, Shandong 250012, China \\ Correspondence should be addressed to Ming Dong; dongming@medmail.com.cn and Li Chen; chenli3@medmail.com.cn
}

Received 5 May 2016; Revised 11 July 2016; Accepted 10 August 2016

Academic Editor: Kamal D. Moudgil

Copyright (C) 2016 Tianyi He et al. This is an open access article distributed under the Creative Commons Attribution License, which permits unrestricted use, distribution, and reproduction in any medium, provided the original work is properly cited.

Purpose. To investigate the effects of Corbrin Capsule (CS-C-Q80), a drug derived from Cordyceps sinensis (Berk.) Sacc., on autoimmune thyroid diseases (AITD). Methods. 44 Patients with Graves's disease (GD) and 56 patients with Hashimoto's thyroiditis (HT) were randomly assigned to treatment group (GD-Tx and HT-Tx) or control group (GD-Ct and HT-Ct). The control groups were given methimazole or levothyroxine only while the treatment groups were given Corbrin Capsule (2.0 g tid) besides the same conventional prescriptions as control groups. Thyroid hormones, thyroid antibodies, and T lymphocyte subsets were quantified at baseline and 24 weeks posttreatment. Results. Significant drop of serum anti-TPO-Ab levels was observed in both GD-Tx and HT-Tx groups. Before treatment, GD patients had higher helper T cells compared to cytotoxic T cells, while HT patients suffered from a nearly inverted proportion of helper $\mathrm{T} /$ cytotoxic $\mathrm{T}$ cells. There was a significant drop of the helper $\mathrm{T} /$ cytotoxic $\mathrm{T}$ cells ratio in GD-Tx to the median of the normal ranges after Corbrin treatment for 24 weeks, while that in HT-Tx was elevated. Conclusion. Corbrin Capsule could restore the balance between helper T and cytotoxic T cells in both GD and HT patients with dual-directional immunomodulatory effects. And it could significantly reduce the autoantibody levels in both GD and HT.

\section{Introduction}

Autoimmune thyroid disease (AITD) is a typical organspecific autoimmune disorder characterized by the elevated titer of autoantibodies and hyperactive $\mathrm{T}$ and $\mathrm{B}$ lymphocytes reactive to thyroid self-antigens [1]. AITD includes Graves' disease, Hashimoto's thyroiditis, and idiopathic hypothyroidism (atrophic Hashimoto's thyroiditis), Graves ophthalmopathy (GO), and postpartum thyroid dysfunction [2]. Among many AITDs, Graves' disease and Hashimoto's thyroiditis together have a prevalence of over $5 \%[3,4]$, making autoimmunity to the thyroid gland the most common autoimmune disease affecting humans [5]. Currently, symptomatic treatments, including antithyroid drugs and thyroid hormone replacement are effective in controlling symptoms. But therapy targeting thyroid autoimmunity is lacking. Lack of intervention in the immunoinflammatory process would result in disease progression and high recurrence rate. In recent years, many studies have indicated that Corbrin Capsule (CS-C-Q80), a drug derived from the traditional Chinese medicine Cordyceps sinensis (CS) Sacc. [6], could exert immune-modulatory effects on many autoimmuneinflammatory diseases including lupus [7], chronic hepatitis [8], chronic kidney disease or kidney transplant $[9,10]$, asthma [11, 12], and diabetes mellitus [13, 14]. In China, some recent study reported that CS could have effects on reducing serum titer of anti-thyroid autoantibodies in AITD. Moreover, it was verified that CS could be effective on cellmediated immunity in animal models of many diseases [15]. However, little is known of their influence on the hyperactive lymphocytes in autoimmune thyroid disease (AITD) in clinical practice. We made efforts to investigate the effects of Corbrin Capsule on the immune disturbance in AITD. 


\section{Materials and Methods}

2.1. Subjects and Ethic Statement. Subjects were randomly selected from newly definitely diagnosed Graves' disease (GD) outpatients $(n=44)$ and Hashimoto's thyroiditis (HT) outpatients $(n=56)$ in the Department of Endocrinology, Qilu Hospital, between Apr 2013 and Aug 2014. A detailed clinical record was kept for each subject including history of disease and physical and laboratory examinations.

Exclusion criteria included unclear diagnosis of autoimmune thyroid diseases (AITDs) or any clues of other autoimmune disorders, recent infections, tumors, fever of any causes, and significantly elevated erythrocyte sedimentation rate. All donors did not receive other immunosuppressive or immunomodulatory drugs for at least 6 months upon sampling and during our treatment. Patients with recurrent Graves before recruitment were not excluded.

Our research was carried out in accordance with the Declaration of Helsinki (2008) of the World Medical Association. This study was approved by the Medical Ethical Committee of Qilu Hospital, Shandong University. Each patient signed a consent document. Baseline demographic parameters are summarized in Table 2.

2.2. Study Design. This study was conducted in a blinded manner. 44 patients with Graves' disease (GD) and 56 patients with hypothyroid Hashimoto's thyroiditis (HT) were randomly assigned into treatment groups (GD-Tx, $n=28$, and HT-Tx, $n=39$ ) or control groups (GD-Ct, $n=16$, and HT-Ct, $n=17)$. The control groups were given conventional antithyroid drugs (for GD) or levothyroxine (for HT) only, while the treatment groups (GD-Tx and HT-Tx) were given Corbrin Capsule ( $2.0 \mathrm{~g}$ tid) besides the conventional prescriptions.

Each patient was followed up for at least 24 weeks. During treatment, necessary adjustments of the antithyroid drugs (for GD) or levothyroxine (for HT) doses were given by professional endocrinologist at each visit.

2.3. The Synopsis of Corbrin Capsule. The main composition of Corbrin Capsule (CS-C-Q80) is fermented powders of Cordyceps sinensis (ascomycetes). Cordyceps is an insect parasitizing fungus and being used as a traditional Chinese herb for more than 2,000 years. The active constituents of $C$. sinensis include cordycepin, polysaccharide, cordycepic acid, nucleosides, ergosterol, aminophenol, and trace elements. The therapeutic applications centered primarily on the key effects of increased oxygen utilization of ATP production and the stabilization of blood sugar metabolism as well. In previous views, its function of immunity regulation plays an important role in the antitumor effects, organ transplantation, and the prevention of kidney, liver, and heart disease [6].

2.4. Determination of Immunological Parameters. Fasting peripheral blood samples were obtained from each donor at 7 to 8 a.m. All samples were operated on within 2 hours after collection. Serum levels of thyroid hormones (including free T3, free T4, and thyroid stimulating hormone (TSH)) and the thyroid related autoantibodies (including TR-Ab,
anti-TG-Ab, and anti-TPO-Ab) were determined by chemiluminescence immunoassay. The peripheral frequencies of $\mathrm{CD}^{+}$(total $\mathrm{T}$ ) cells and $\mathrm{CD}^{+} \mathrm{CD}^{+}$(helper $\mathrm{T}$ ) and $\mathrm{CD}^{+} \mathrm{CD}^{+}$(cytotoxic $\mathrm{T}$ ) cells were quantified by flow cytometry at each time of follow-up (baseline, 4 weeks, 12 weeks, and 24 weeks after treatment). All tests were conducted in the centralized standardized laboratory in Qilu Hospital of Shandong University. Normal ranges and abbreviation of all relative indexes were listed in Table 1.

2.5. Statistical Analysis. All data are presented as mean \pm $\mathrm{SD}$ or median \pm quartile according to data distribution. Differences of parameters between each group were determined by Student's $t$-test unless the data were apparently skewed-distributed. All tests were performed and figures were generated by SPSS 18.0 system. $P$ value less than 0.05 was considered statistically significant.

\section{Results}

3.1. Baseline Characteristics of Subjects. 44 patients with Graves' disease (GD) and 56 patients with hypothyroid Hashimoto's thyroiditis (HT) were randomly assigned to treatment groups (GD-Tx and HT-Tx) or control groups (GD-Ct and HT-Ct), respectively. The average age of patients included in this study was $36.2 \pm 14.19$ versus $37.24 \pm 10.26$ years in GD-Tx and GD-Ct group and $41.40 \pm 13.76$ versus $43.82 \pm 12.48$ years in HT-Tx and HT-Ct group, respectively. The baseline demographic data is given in Table 2. Comparing the treatment and control groups of GD and $\mathrm{HT}$, respectively, there were no significant differences between body mass index (BMI), blood pressure (BP), thyroid function, levels of thyroid related autoantibodies, and $\mathrm{T}$ lymphocyte populations $(P>0.05)$.

3.2. Therapeutic Effect of CS on GD Patients. At the end of treatment between GD-Tx and GD-Ct groups, the mean serum FT3 level $(5.02 \pm 3.55$ versus $6.10 \pm 1.18 \mathrm{pmol} / \mathrm{L}$, $P=0.954)$ and FT4 levels $(14.90 \pm 2.13$ versus $18.52 \pm$ $2.73 \mathrm{pmol} / \mathrm{L}, P=0.746)$ and median serum TSH level (1.34 \pm 1.16 versus $1.14 \pm 1.07, P=0.741)$ showed no difference. The autoimmune data in GD-Tx group were given in Table 3. There were an increase of $\mathrm{CD}^{+}$(increased by $13.5 \%, P=$ 0.047 ), a decrease of $\mathrm{CD}^{+}$(decreased by $8.98 \%, P=0.044$ ), and a significant decrease in CD4/CD8 ratio $(P=0.022)$. Moreover, TPO-Ab and TR-Ab declined by $40.06 \%$ and $46.94 \%$ of baseline, respectively $(P=0.012$ and $P<0.001)$ (Figure 1).

3.3. Therapeutic Effect of CS on HT Patients. Between HTTx and HT-Ct groups, thyroid functions were improved compared to the baseline at the end of treatment. Neither the mean serum FT4 levels $(14.91 \pm 2.14$ versus $14.33 \pm$ $1.78 \mathrm{pmol} / \mathrm{L}, P=0.805)$ nor serum TSH level $(3.36 \pm$ 1.19 versus $3.09 \pm 2.07, P=0.386$ ) showed statistical difference with the control group. However, TPO-Ab and TGAb declined by $51.30 \%$ and $39.49 \%$ of baseline, respectively ( $P=0.022$ and $P=0.037$ compared with HT-Ct) (Figure 1). The autoimmune data in HT-Tx group were given in Table 4. 
TABLE 1: Abbreviations and normal ranges.

\begin{tabular}{lccc}
\hline Abbreviation & Full name & Normal ref. range & Unit \\
\hline fT3 & Free triiodothyronine & $2.3-6.3$ & $\mathrm{pmol} / \mathrm{L}$ \\
fT4 & Free tetraiodothyronine & $10.3-24.5$ & $\mathrm{pmol} / \mathrm{L}$ \\
TSH & Thyroid stimulating hormone & $0.35-5.5$ & $\mathrm{UIU} / \mathrm{mL}$ \\
TPO-Ab & Anti-thyroid peroxidase antibody & $0-60$ & $\mathrm{U} / \mathrm{mL}$ \\
TR-Ab & Thyrotrophin receptor antibody & $0.01-30$ & $\mathrm{IU} / \mathrm{mL}$ \\
TG-Ab & Antithyroglobulin antibodies & $0-4.11$ & $\mathrm{IU} / \mathrm{mL}$ \\
CD3 & Cluster of differentiation 3 & $55-80$ & $\%$ \\
CD4 & Cluster of differentiation 4 & $25-45$ & $\%$ \\
CD8 & Cluster of differentiation 8 & $15-35$ & $\%$ \\
CD4/CD8 & Ratio of CD4 and CD8 & $1.0-2.0$ & - \\
\hline
\end{tabular}

The abbreviations and normal ranges of all indexes. All the reference ranges are from the endocrinology laboratory and immunology laboratory in Qilu Hospital among Chinese population.

TABLE 2: Baseline characteristics of subjects.

\begin{tabular}{|c|c|c|c|c|c|c|}
\hline & \multicolumn{3}{|c|}{ GD } & \multicolumn{3}{|c|}{ HT } \\
\hline & $\operatorname{Tx}(n=28)$ & $\mathrm{Ct}(n=16)$ & $P$ value & $\operatorname{Tx}(n=39)$ & $\mathrm{Ct}(n=17)$ & $P$ value \\
\hline Age (year) & $36.2 \pm 14.19$ & $37.24 \pm 10.26$ & 0.156 & $41.40 \pm 13.76$ & $43.82 \pm 12.48$ & 0.168 \\
\hline Gender (male/female) & $14 / 28$ & $6 / 16$ & 0.492 & $11 / 39$ & $7 / 17$ & 0.254 \\
\hline BMI $\left(\mathrm{kg} / \mathrm{m}^{2}\right)$ & $21.11 \pm 2.46$ & $22.94 \pm 3.16$ & 0.061 & $23.13 \pm 3.57$ & $22.83 \pm 4.01$ & 0.071 \\
\hline $\mathrm{SBP}(\mathrm{mmHg})$ & $117.87 \pm 12.26$ & $114.55 \pm 11.43$ & 0.112 & $120.25 \pm 15.24$ & $114.27 \pm 17.64$ & 0.057 \\
\hline $\mathrm{DBP}(\mathrm{mmHg})$ & $76.47 \pm 10.23$ & $78.58 \pm 9.15$ & 0.135 & $86.08 \pm 13.44$ & $77.98 \pm 10.21$ & 0.106 \\
\hline $\operatorname{HR}(/ \min )$ & $88.53 \pm 5.82$ & $86.89 \pm 4.53$ & 0.171 & $75.42 \pm 9.32$ & $78.36 \pm 8.34$ & 0.770 \\
\hline FT3 (pmol/L) & $9.52 \pm 7.53$ & $8.96 \pm 1.43$ & 0.308 & $3.39 \pm 1.01$ & $3.42 \pm 1.12$ & 0.640 \\
\hline FT4 (pmol/L) & $23.01 \pm 17.26$ & $25.93 \pm 10.46$ & 0.112 & $11.83 \pm 3.64$ & $10.47 \pm 3.59$ & 0.318 \\
\hline TSH $(\mu \mathrm{IU} / \mathrm{L})$ & $0.07 \pm 0.13$ & $0.09 \pm 0.17$ & 0.451 & $10.94 \pm 6.52$ & $9.75 \pm 7.21$ & 0.522 \\
\hline TPO-Ab (IU/mL) & $659.28 \pm 585.89$ & $672.39 \pm 463.51$ & 0.086 & $820.51 \pm 372.45$ & $829.39 \pm 388.29$ & 0.455 \\
\hline TG-Ab (IU/mL) & - & - & - & $547.8 \pm 331.45$ & $593.28 \pm 273.65$ & 0.383 \\
\hline TR-Ab (IU/mL) & $34.51 \pm 17.97$ & $31.16 \pm 11.46$ & 0.128 & - & - & - \\
\hline $\mathrm{CD}^{+}(\%)$ & $66.98 \pm 9.40$ & $67.62 \pm 8.36$ & 0.196 & $69.56 \pm 8.57$ & $67.62 \pm 8.36$ & 0.146 \\
\hline $\mathrm{CD}^{+}(\%)$ & $38.30 \pm 5.37$ & $36.96 \pm 2.29$ & 0.227 & $34.47 \pm 6.74$ & $33.96 \pm 4.29$ & 0.238 \\
\hline $\mathrm{CD}^{+}(\%)$ & $21.93 \pm 4.46$ & $21.98 \pm 6.56$ & 0.348 & $29.07 \pm 7.06$ & $28.98 \pm 6.54$ & 0.074 \\
\hline $\mathrm{CD}^{+} / \mathrm{CD}^{+}$ratio & $1.86 \pm 0.66$ & $1.89 \pm 0.79$ & 0.105 & $1.23 \pm 0.55$ & $1.19 \pm 0.68$ & 0.089 \\
\hline
\end{tabular}

44 Graves disease (GD) outpatients and 56 hypothyroid Hashimoto's thyroiditis (HT) outpatients were newly definitely diagnosed and enrolled. All general data and thyroid hormones and related antibodies and cell immune indicators were listed. GD-Tx: GD treatment group; GD-Ct: GD control group; HT-Tx: HT treatment group; and HT-Ct: HT control group.

TABLE 3: Baseline and end of treatment of subjects in Graves' disease.

\begin{tabular}{|c|c|c|c|c|c|c|}
\hline & \multicolumn{3}{|c|}{ GD-Tx } & \multicolumn{3}{|c|}{ GD-Ct } \\
\hline & Baseline & End of treatment & $P$ value & Baseline & End of treatment & $P$ value \\
\hline FT3 (pmol/L) & $9.52 \pm 7.53$ & $5.02 \pm 3.55$ & 0.098 & $8.96 \pm 1.43$ & $6.10 \pm 1.18$ & 0.077 \\
\hline FT4 (pmol/L) & $23.01 \pm 17.26$ & $14.90 \pm 2.13$ & 0.130 & $25.93 \pm 10.46$ & $18.52 \pm 2.73$ & 0.340 \\
\hline TSH $(\mu \mathrm{IU} / \mathrm{L})$ & $0.07 \pm 0.13$ & $1.34 \pm 1.16$ & 0.042 & $0.09 \pm 0.17$ & $1.14 \pm 1.07$ & $<0.001$ \\
\hline TPO-Ab (IU/mL) & $659.28 \pm 585.85$ & $434.99 \pm 229.93$ & 0.012 & $672.39 \pm 463.51$ & $575.64 \pm 361.87$ & 0.313 \\
\hline TR-Ab (IU/mL) & $34.51 \pm 17.97$ & $11.57 \pm 4.07$ & $<0.001$ & $31.16 \pm 11.46$ & $27.07 \pm 8.14$ & 0.083 \\
\hline $\mathrm{CD}^{+}(\%)$ & $66.98 \pm 9.40$ & $66.31 \pm 9.70$ & 0.462 & $67.62 \pm 8.36$ & $66.98 \pm 5.31$ & 0.761 \\
\hline $\mathrm{CD} 4^{+}(\%)$ & $38.30 \pm 5.37$ & $34.86 \pm 2.03$ & 0.044 & $36.96 \pm 2.29$ & $36.88 \pm 3.46$ & 0.947 \\
\hline $\mathrm{CD}^{+}(\%)$ & $21.93 \pm 4.46$ & $24.89 \pm 3.29$ & 0.047 & $21.98 \pm 6.56$ & $23.84 \pm 5.12$ & 0.150 \\
\hline $\mathrm{CD} 4 / \mathrm{CD} 8$ ratio & $1.86 \pm 0.66$ & $1.42 \pm 0.19$ & 0.022 & $1.89 \pm 0.79$ & $1.60 \pm 0.43$ & 0.209 \\
\hline
\end{tabular}

The data of GD-Tx group and GD-Ct group were compared between the start and end of treatment (24 weeks). In the GD-Tx groups, there were a significant decrease of $\mathrm{CD}_{4}^{+}$, an increase of $\mathrm{CD}^{+}$, and a decreased $\mathrm{CD} 4 / \mathrm{CD} 8$ ratio compared to the baseline. None of the parameters changed significantly in GD-Ct group. 


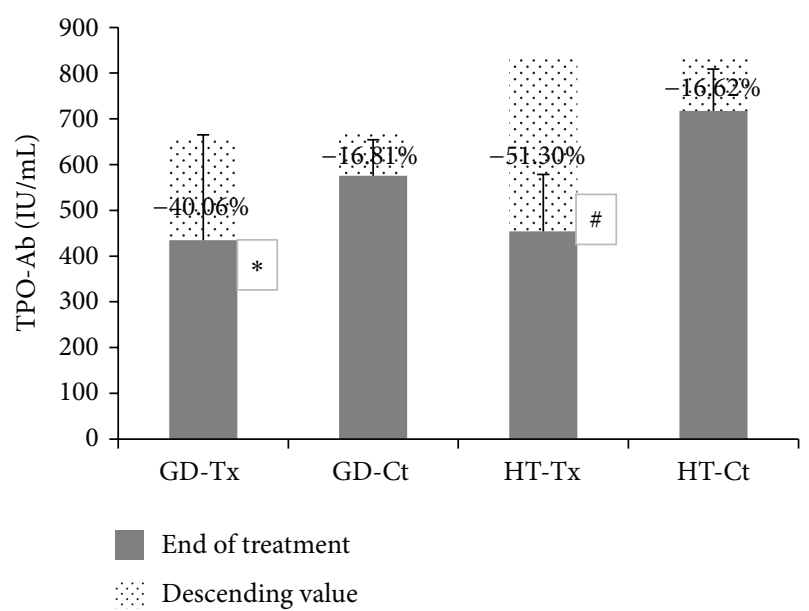

(a) Alternation of TPO-Ab

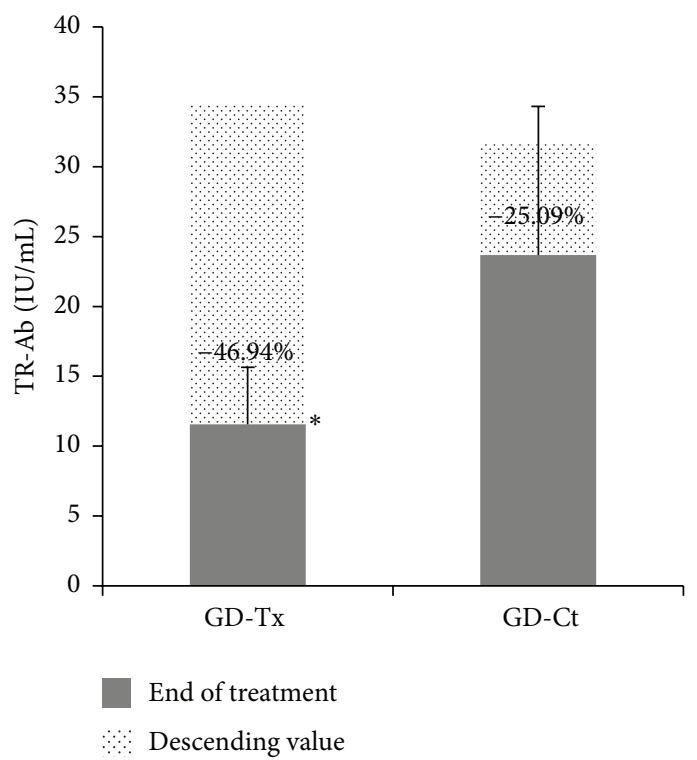

(b) Alternation of TR-Ab

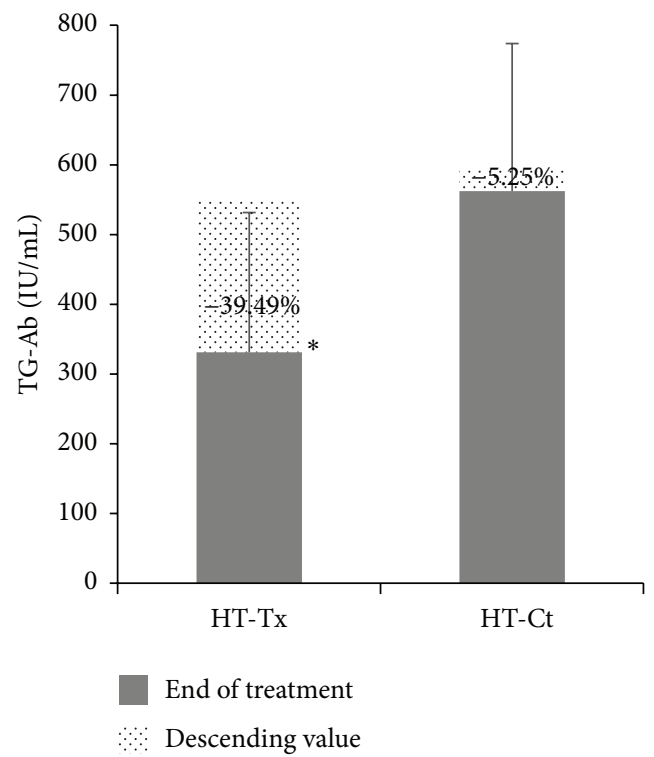

(c) Alternation of TG-Ab

FIGURE 1: Alternations in peripheral autoantibody levels in AITD patients. Alternations in peripheral different kinds of thyroid related autoantibodies in treatment groups (GD-Tx and HT-Tx) and control groups (GD-Ct and HT-Ct), respectively. (a) Thyroid peroxidase antibody (TPO-Ab). ${ }^{*} P=0.020$, compared with GD-Ct; ${ }^{*} P=0.003$, compared with HT-Ct. (b) Thyrotropin receptor antibody (TR-Ab). ${ }^{*} P<0.001$, compared with GD-Ct. (c) Thyroglobulin antibody (TG-Ab). ${ }^{*} P=0.037$, compared with HT-Ct.

There were a decrease in total $\mathrm{CD}^{+}$cells (decreased by $7.82 \%$, $P=0.051)$, an increase of $\mathrm{CD}^{+}(P=0.791)$, a pronounced decrease of $\mathrm{CD} 8^{+}$(decreased by $17.7 \%, P=0.031$ ), and a relative increase of $\mathrm{CD} 4 / \mathrm{CD} 8$ ratio $(P=0.024)$ after CS treatment.

As normal or hypothyroid HT were all included, we further divided the HT-Tx group into two groups, namely, euthyroidism HT-Tx group and hypothyroid HT-Tx group (data in supplement table in Supplementary Material available online at http://dx.doi.org/10.1155/2016/1360386). It was found that the decrease of TPO-Ab in euthyroidism HT-Tx group and the decrease of TG-Ab in hypothyroidism HT-Tx were more obvious, respectively. As for the CD4/CD8 ratio, the therapeutic effect of Cordyceps sinensis Sacc. was more significant on the hypothyroidism HT patients.

3.4. Cross-Sectional Comparison of Treatment and Control Group during 24 Weeks of Treatment. Generally, there was a significant tendency of immune parameter changes in the longitudinal follow-up in Corbrin treatment groups compared to those in control groups (Figures 2 and 3). The comparison, respectively, between GD-Tx and GD-Ct and HT-Tx 


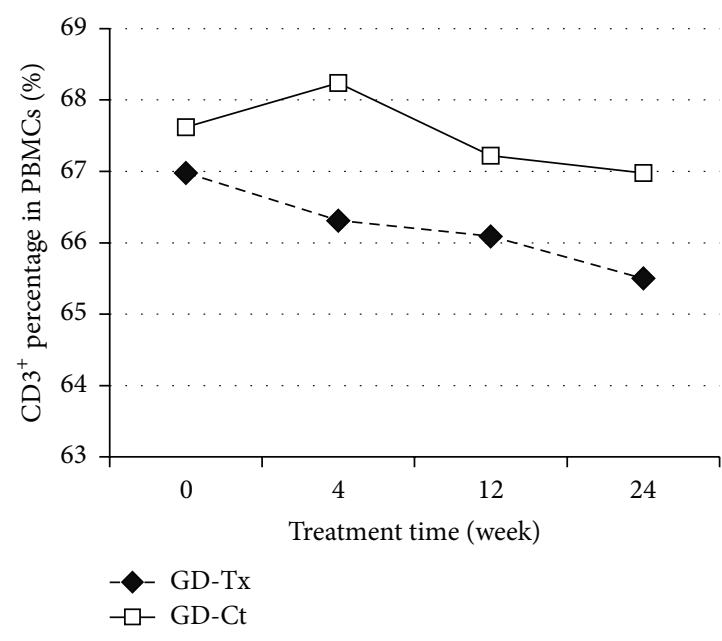

(a) Alternations of $\mathrm{CD}^{+}$cell

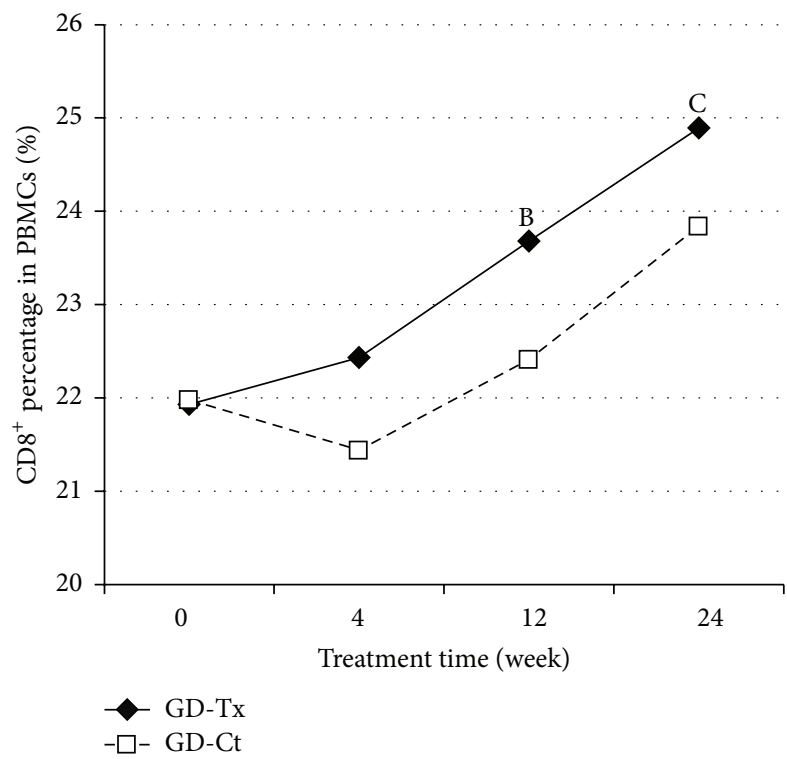

(c) Alternations of $\mathrm{CD} 8^{+}$cell

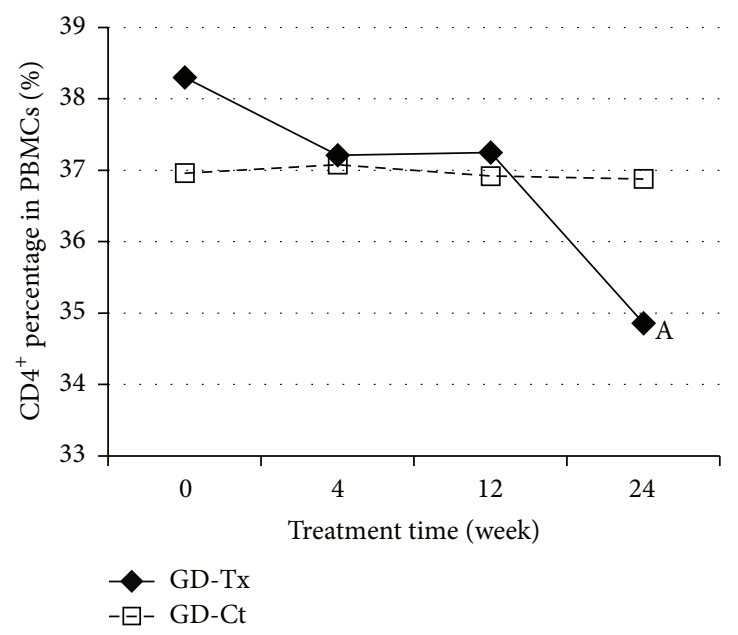

(b) Alternations of $\mathrm{CD} 4^{+}$cell

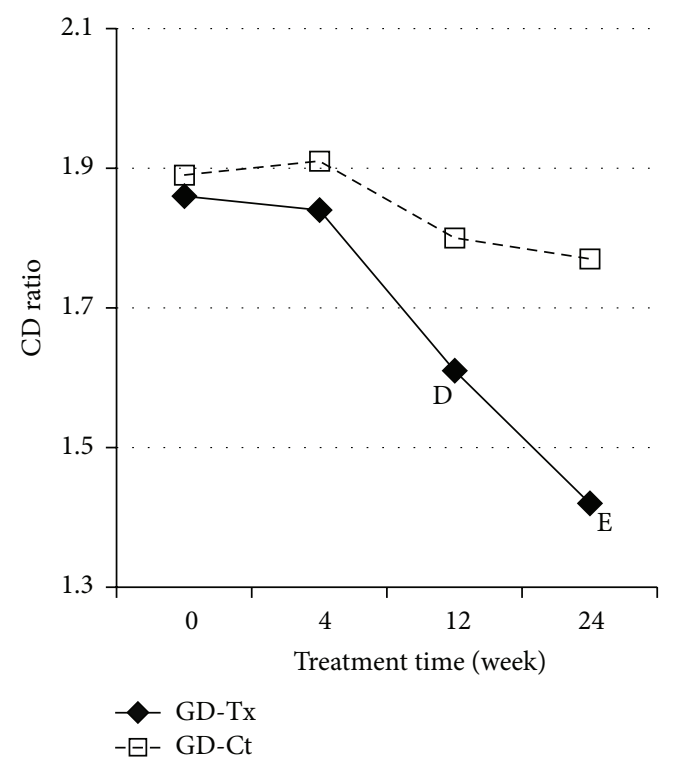

(d) Alternations of CD ratio

Figure 2: Alternations of peripheral T cell subsets along with treatment time in Graves' disease groups. Alternations in peripheral different kinds of $\mathrm{T}$ cell subsets in treatment groups (GD-Tx) and control groups (GD-Ct) of Graves disease. Four pictures are shown as follows: (a) $\mathrm{CD}^{+}$percentage in PBMCs (\%), (b) CD $4^{+}$percentage in PBMCs $(\%),{ }^{\mathrm{A}} \mathrm{P}=0.044$, (c) $\mathrm{CD} 8^{+}$percentage in PBMCs $(\%),{ }^{\mathrm{B}} \mathrm{P}=0.051$ and ${ }^{\mathrm{C}} \mathrm{P}=0.047$, and (d) $\mathrm{CD}^{+} / \mathrm{CD} 8^{+}$ratio, ${ }^{\mathrm{D}} \mathrm{P}=0.047$ and ${ }^{\mathrm{E}} \mathrm{P}=0.022$.

and HT-Ct group revealed the beneficial effect of combined therapy of Cordyceps sinensis Sacc. with conventional therapy (Tables 3 and 4).

\section{Discussion}

There are many organ-specific autoimmune disorders including autoimmune thyroid disease (AITD) [4], autoimmune arthritis [16], insulin-dependent diabetes mellitus [17], and myasthenia gravis [18] which is the most common disease in the clinical practice. AITD could lead to both hypothyroidism and hyperthyroidism. Graves' disease (GD) is usually the principal culprit for hyperthyroidism, whereas Hashimoto's thyroiditis (HT) is responsible for most cases of hypothyroidism in AITD. Although the detailed mechanisms for AITD largely remain unknown, the similar immunemediated mechanisms of disease including lymphocytes hyperactivation and infiltration are the key processes in the development of both GD and HT [5]. Currently, interest in $\mathrm{T}$ lymphocyte subsets has arisen because of their critical role in regulation of the autoimmune process. $\mathrm{CD} 3^{+} \mathrm{CD} 4^{+}$ and $\mathrm{CD}^{+} \mathrm{CD}^{+}$cells are the two major subsets in $\mathrm{CD}^{+}$ lymphocytes (namely, T cells). $\mathrm{CD}^{+} \mathrm{CD}^{+}$cells are traditionally called $\mathrm{T}$ helper cells since they assist other white blood cells in immunologic processes, including maturation of $\mathrm{B}$ cells into plasma cells and activation of $\mathrm{CD} 3^{+} \mathrm{CD} 8^{+}$ (namely, cytotoxic/suppressor T) cells. In both the entities of AITD, there is a broken balance between the T cell subsets. 


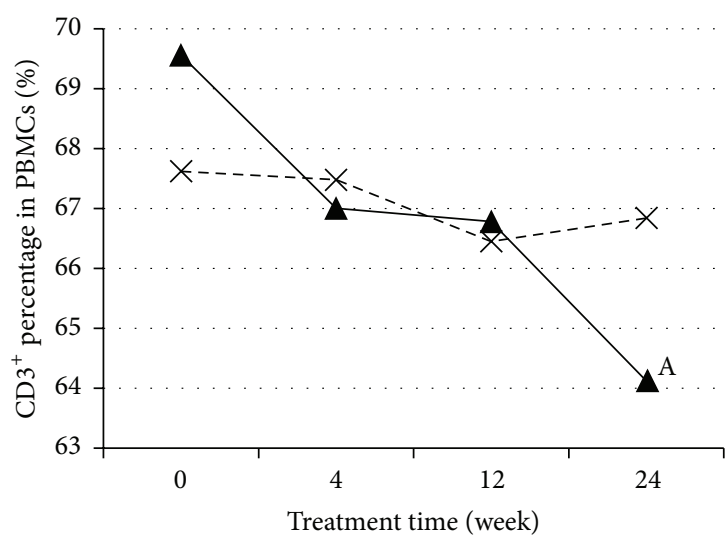

- HT-Tx $-\rtimes-$ HT-Ct

(a) Alternations of $\mathrm{CD}^{+}$cell

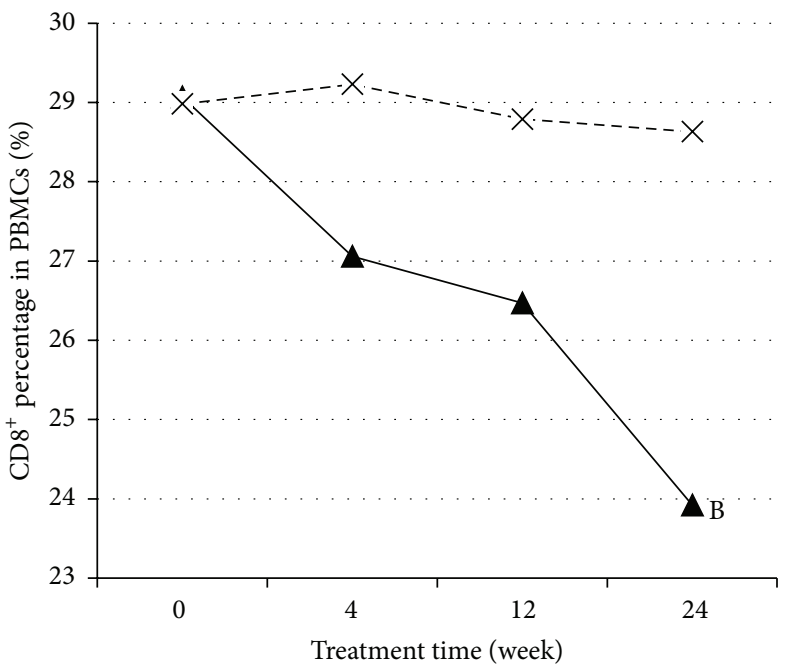

- HT-Tx

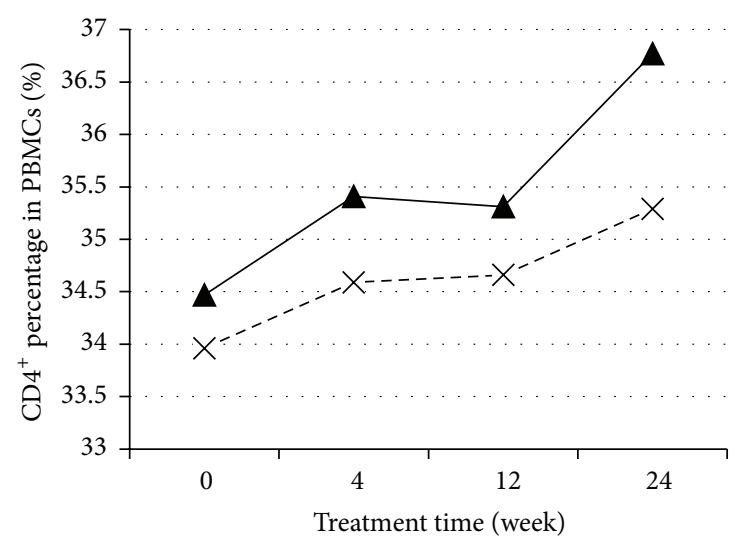

- HT-Tx

$-\mathrm{X}-\mathrm{HT}-\mathrm{Ct}$

(b) Alternations of $\mathrm{CD} 4^{+}$cell

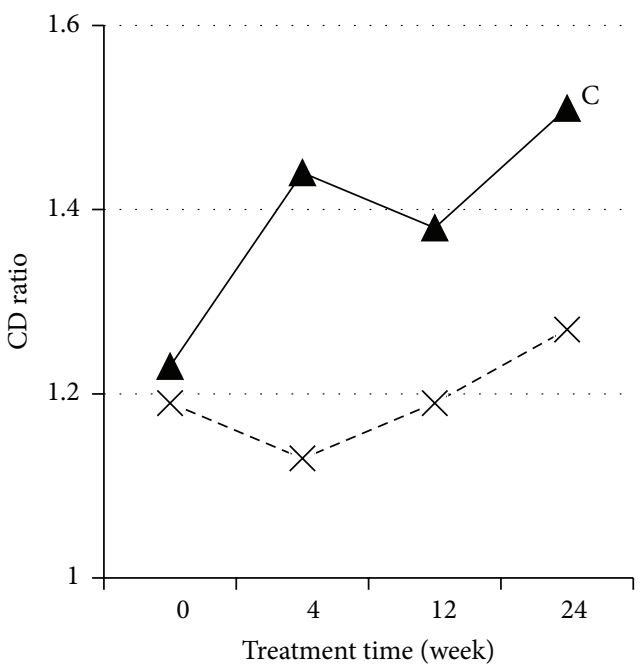

HT-Tx

(c) Alternations of $\mathrm{CD} 8^{+}$cell

FIgURE 3: Alternations of peripheral T cell subsets along with treatment time in Hashimoto's thyroiditis (HT) groups. Alternations in peripheral different kinds of T cell subsets in treatment group (HT-Tx) and control group (HT-Ct) of Graves disease. Four pictures are, namely, in turn (a) $\mathrm{CD}^{+}$percentage in PBMCs (\%), ${ }^{\mathrm{A}} \mathrm{P}=0.051$, (b) $\mathrm{CD}^{+}$percentage in PBMCs (\%), (c) $\mathrm{CD} 8^{+}$percentage in PBMCs (\%), ${ }^{\mathrm{B}} \mathrm{P}=0.031$, and (d) $\mathrm{CD} 4^{+} / \mathrm{CD} 8^{+}$ratio, ${ }^{\mathrm{C}} \mathrm{P}=0.024$.

In fact, it has been suggested for more than two decades that $\mathrm{T}$ lymphocytes play different roles in the pathogenesis of the two major archetypes in human AITD [19]. A decrease in the CD4/CD8 ratio in hypothyroid Hashimoto's thyroiditis patients has long been observed, in contrast to the increase in the ratio in Graves' hyperthyroidism [20]. There was a decrease in $\mathrm{CD}^{+}$(suppressor/cytotoxic) T cells in the peripheral blood of patients with hyperthyroid Graves' disease [21]. And no cytotoxic effect of T cytotoxic/suppressor $\mathrm{CD}^{+}$cells on thyrocytes was observed in Graves' disease [22]. Actually, the pathogenic factors in Graves' hyperthyroidism are the autoaggressive $\mathrm{CD} 4^{+}$cells which drive the maturation of the plasma cells and secretion of stimulatory autoantibody targeting thyrotrophin (TSH) receptor (i.e., TR$\mathrm{Ab})$. In hypothyroid HT, however, the downregulated or even inverted CD4/CD8 ratio results from increased frequency of $\mathrm{CD}^{+}$cells, whose infiltration and cytolytic effects could be directly responsible for the destruction of the follicular thyroid and thyrocytes [23]. Thus, the divergence of $\mathrm{T}$ cell polarization may exactly explain for the main reason for the completely opposite clinical manifestations in GD and HT.

Cordyceps sinensis (CS) is an entomogenous fungus used as a tonic food and Chinese medicine to replenish health $[6,24]$. Corbrin Capsule is a representative drug of Cordyceps sinensis (CS) Sacc. The biologic active component of Corbrin Capsule is $100 \%$ fermented powder of Cordyceps sinensis 
TABLE 4: Baseline and end of treatment of subjects in Hashimoto's thyroiditis.

\begin{tabular}{|c|c|c|c|c|c|c|}
\hline & \multicolumn{3}{|c|}{ HT-Tx } & \multicolumn{3}{|c|}{ HT-Ct } \\
\hline & Baseline & End of treatment & $P$ value & Baseline & End of treatment & $P$ value \\
\hline FT3 (pmol/L) & $3.39 \pm 1.01$ & $4.19 \pm 1.03$ & 0.469 & $3.42 \pm 1.12$ & $3.92 \pm 1.30$ & 0.754 \\
\hline FT4 (pmol/L) & $11.83 \pm 3.64$ & $14.91 \pm 2.14$ & 0.002 & $10.47 \pm 3.59$ & $14.33 \pm 1.78$ & 0.003 \\
\hline TSH $(\mu \mathrm{IU} / \mathrm{L})$ & $10.94 \pm 6.52$ & $3.36 \pm 1.19$ & 0.003 & $9.75 \pm 7.21$ & $3.09 \pm 2.07$ & 0.031 \\
\hline TPO-Ab (IU/mL) & $820.51 \pm 572.4$ & $454.05 \pm 227.96$ & 0.022 & $829.39 \pm 388.29$ & $717.19 \pm 213.63$ & 0.217 \\
\hline TG-Ab (IU/mL) & $547.8 \pm 331.45$ & $331.45 \pm 124.61$ & 0.037 & $593.28 \pm 273.65$ & $561.82 \pm 196.97$ & 0.603 \\
\hline $\mathrm{CD}^{+}(\%)$ & $69.56 \pm 8.57$ & $64.12 \pm 8.18$ & 0.051 & $67.62 \pm 8.36$ & $68.11 \pm 2.55$ & 0.838 \\
\hline $\mathrm{CD}^{+}(\%)$ & $34.47 \pm 6.74$ & $36.77 \pm 4.32$ & 0.791 & $33.96 \pm 4.29$ & $34.00 \pm 2.19$ & 0.962 \\
\hline $\mathrm{CD}^{+}(\%)$ & $29.07 \pm 7.06$ & $23.92 \pm 6.20$ & 0.031 & $28.98 \pm 6.54$ & $25.91 \pm 3.17$ & 0.295 \\
\hline $\mathrm{CD} 4 / \mathrm{CD} 8$ ratio & $1.23 \pm 0.55$ & $1.51 \pm 0.46$ & 0.024 & $1.19 \pm 0.68$ & $1.33 \pm 0.21$ & 0.457 \\
\hline
\end{tabular}

The data of HT-Tx group and HT-Ct group were compared between the start and end of treatment (24 weeks). In the HT-Tx group, there were an increase of $\mathrm{CD}^{+}$, a significant decrease of $\mathrm{CD}^{+}$, and an increased $\mathrm{CD} 4 / \mathrm{CD} 8$ ratio compared to the baseline. None of the parameters changed significantly in HT-Ct group.

(CS-C-Q80) [25]. Corbrin Capsule has been reported to have immunomodulatory effects on many autoimmuneinflammatory diseases including cerebral disease [26] (in rat), type 1 diabetes, asthma, chronic obstructive pulmonary disease [27], and chronic nephritic disease [9]. In China, some recent studies reported that CS could significantly reduce serum titer of anti-thyroid autoantibody in both GD and HT. Moreover, it was verified that CS could be effective on cell-mediated immunity in animal models of many diseases [15]. However, there is no evidence on the immunomodulatory effects of CS-C-Q80 on T cell polarization in AITD patients. Since the divergence in T cell polarization in GD and hypothyroid HT patients plays an important role in the outcome of AITD, we investigated the effect of Corbrin Capsule on the number and distribution of peripheral blood T lymphocyte subsets in patients with GD and HT.

It had been observed for a long time that there was a reduction in the suppressor $T$ cell subset and increase in the helper $\mathrm{T}$ cell subset in peripheral blood from GD patients [28]. Further study suggested that the decreases in the percentage of $\mathrm{CD}^{+}$cells (cytotoxic/suppressor cell) are associated with abnormalities in the immune system [29]. Aust et al. revealed that $\mathrm{CD}^{+}$cells, as well as NK cells, may help prevent pathogenic B cell infiltration of the thyroid [30]. It is well documented that proinflammatory Thl-type cytokines, including tumor necrosis factor- $\alpha$ (TNF- $\alpha)$, IFN- $\gamma$, and IL-2, play pivotal roles in the pathogenesis of GD in the active state [25-27]. Th2 rather than Th1 response is in the domination nonactive state. The Th2 dominance subsequently facilitates the $\mathrm{T}$ cell-dependent $\mathrm{B}$ cell activation and the secretion of stimulatory autoantibody, TS-Ab, from mature pathogenic B (plasma) cells into blood, leading to hyperactive thyrocyte functions and hyperthyroxinemia [31]. Since $\mathrm{CD}^{+}$cells can work to counteract Th2 dominance, suppression of $\mathrm{CD} 8^{+}$ cells by this Th2 response may accentuate the symptoms of GD. Moreover, the increase of $\mathrm{CD}^{+}$cells, which indicates hyperactivation of $\mathrm{T}$ helper subset, could also promote the maturation of pathogenic plasma cells from B lymphocyte, thus exacerbating the hyperthyroidism in GD. In this study, we observed a higher $\mathrm{CD} 4^{+} / \mathrm{CD}^{+}$ratio in untreated GD patients, which was in accordance with previous publications. After treatment with antithyroid drugs combined with CS-C$\mathrm{Q} 80$, the $\mathrm{CD}^{+} / \mathrm{CD}^{+}$ratio returned to the median of normal ranges $(P=0.022)$ accompanied by a significant drop of TR$\mathrm{Ab}$ and TPO-Ab levels. However, there were no significant changes in these immune parameters in GD-Ct before and after traditional treatment suggesting a suppressive effect of humoral autoimmune reaction of CS-C-Q80 on GD.

HT, also referred to as chronic lymphocytic thyroiditis, is an autoimmune disease in which the thyroid gland is attacked by a variety of cell- and antibody-mediated immune processes [32]. A decrease in the CD4/CD8 ratio in HT hypothyroid patients was observed [23], in contrast to an increase in the ratio in autoimmune hyperthyroid patients. This suggests a different role for T lymphocytes in the pathogenesis of the two major human autoimmune thyroid diseases $[22,23]$. The anti-TG and anti-TPO autoantibodies are usually seen elevated in HT, which is responsible for the subsequent antibody-mediated immune processes. Although a small percentage of patients may have nondetectable antibodies present, cell-mediated cytotoxicity is a substantial factor behind the apoptotic fall-out in HT. Activation of cytotoxic $\mathrm{T}\left(\mathrm{CD}^{+} \mathrm{CD}^{+}\right)$cells in response to cell-mediated immune response affected by $\mathrm{T}$ helper $\left(\mathrm{CD}^{+} \mathrm{CD}^{+}\right)$cells is central to thyrocyte destruction. $\mathrm{CD}^{+} \mathrm{T}$ cells have cytotoxic properties in Hashimoto's thyroiditis [23] and can induce thyroid epithelial cell hyperplasia and fibrosis [33]. These indicate that clonal expansion of $\mathrm{CD}^{+} \mathrm{T}$ cells in HT can be detected in peripheral blood and support the role of $\mathrm{CD}^{+} \mathrm{T}$ cells in cell-mediated autoimmune attacks on the thyroid gland in HT [34]. During the natural course of HT, most patients are euthyroid at the beginning while half of them develop hypothyroidism during long-term follow-up [35]. Few of them suffered from a period of hyperthyroidism mostly due to destruction of follicular thyroid and release of thyroid hormones as what happened in other types of thyroiditis mostly among children. The latter usually goes undetected as it is transient, lasting only a few months [32]. Thus the natural 
course of HT is attributed to and reflects the different stages of autoimmune process targeting thyroid. Conventional treatment of L-thyroxine could efficiently restore euthyroidism after 12 weeks but without the drop of antibodies. Though about $8 \%$ of these patients maintain a normal thyroid function after withdrawal of L-thyroxine replacement for no significant change in $\mathrm{CD}^{+}$percentages, $\mathrm{CD} 8^{+}$percentages in most HT patients are higher and could cause a chronic nature. In this study, we focused mostly on HT patients without hyperthyroid. All these patients had a significantly elevated anti-TPO-Ab and anti-TG-Ab levels and impaired thyroid function (TSH) which were characterized by lower $\mathrm{CD}^{+} \mathrm{T}$ cells and higher $\mathrm{CD}^{+} \mathrm{T}$ cells as seen in Table 2 . With the treatment of Corbrin Capsule, there was a significant drop in anti-TPO-Ab level and total $\mathrm{CD}^{+}$cells and $\mathrm{CD} 8^{+} \mathrm{T}$ cells. The increased $\mathrm{CD}^{+} / \mathrm{CD}^{+}$ratio $(P=0.024)$ indicates that CSC-Q80 could correct the cellular immune disorder, at least partially, by inhibiting $\mathrm{CD}^{+}$expansion.

Of note, a number of studies have shown that CS can positively stimulate the activation of T lymphocytes, B lymphocytes, natural killer cells, and macrophages [36]. In our study, we found that CS-C-Q80 could also inhibit the proliferation of $\mathrm{CD}^{+} \mathrm{T}$ cells in cytotoxic T-dominant autoimmune status or $\mathrm{CD}^{+} \mathrm{T}$ cells in helper $\mathrm{T}$-dominant (especially Th2-dominant) autoimmune status and restore the helper $\mathrm{T} /$ cytotoxic $\mathrm{T}$ cells balance to the median value of normal ranges. These results suggest a bidirectional immunomodulatory effect of CS under different immunological and inflammatory context [37].

\section{Conclusion}

GD and HT patients have different pathological changes in helper T/cytotoxic T cells polarization. CS-C-Q80 could restore the balance between helper $\mathrm{T}$ and cytotoxic $\mathrm{T}$ cells in both GD and HT patients with dual-directional immunomodulatory effects. In addition, it could significantly reduce the autoantibody levels in both GD and HT and thus could attenuate the immune disturbance in both types of AITD. Since the immune disturbance is considered the culprit of the recurrence for GD and to be of a chronic nature for typical HT, the long-term effects of CS-C-Q80 on preventing relapse of AITD are warranted in the near future.

\section{Competing Interests}

The authors declare that they have no financial or other competing interests.

\section{Authors' Contributions}

Ming Dong and Li Chen contributed equally. All authors read and approved the final manuscript.

\section{Acknowledgments}

This study was financially supported by the National Natural Science Foundation of China (Grants no. 81370943 and no. 81500631), National Health and Family Planning Commission Foundation (Grant no. 201502007), Shandong
Natural Science Foundation (Grants no. BS2015YY011 and no. ZR2013HQ054), Science and Technology Department of Shandong Province Foundation (Grant no. 2014ZZCX02201), and Jinan Clinical Science and Technology Innovation Program (a new-mode establishment of diabetic prevention and treatment based on remote wireless blood sugar management system).

\section{References}

[1] C. Balázs, "The role of hereditary and environmental factors in autoimmune thyroid diseases," Orvosi Hetilap, vol. 153, no. 26, pp. 1013-1022, 2012.

[2] M. F. Prummel, T. Strieder, and W. M. Wiersinga, "The environment and autoimmune thyroid diseases," European Journal of Endocrinology, vol. 150, no. 5, pp. 605-618, 2004.

[3] D. L. Jacobson, S. J. Gange, N. R. Rose, and N. M. H. Graham, "Epidemiology and estimated population burden of selected autoimmune diseases in the United States," Clinical Immunology and Immunopathology, vol. 84, no. 3, pp. 223-243, 1997.

[4] A. Antonelli, S. M. Ferrari, A. Corrado, A. Di Domenicantonio, and P. Fallahi, "Autoimmune thyroid disorders," Autoimmunity Reviews, vol. 14, no. 2, pp. 174-180, 2015.

[5] H. J. Lee, C. W. Li, S. S. Hammerstad, M. Stefan, and Y. Tomer, "Immunogenetics of autoimmune thyroid diseases: a comprehensive review," Journal of Autoimmunity, vol. 64, pp. 82-90, 2015.

[6] X. Zhou, Z. Gong, Y. Su, J. Lin, and K. Tang, "Cordyceps fungi: natural products, pharmacological functions and developmental products," The Journal of Pharmacy and Pharmacology, vol. 61, no. 3, pp. 279-291, 2009.

[7] L. Lu, "Study on effect of Cordyceps sinensis and artemisinin in preventing recurrence of lupus nephritis," Chinese Journal of Integrated Traditional and Western Medicine, vol. 22, no. 3, pp. 169-171, 2002.

[8] H. Y. Gong, K. Q. Wang, and S. G. Tang, "Effects of cordyceps sinensis on Tlymphocyte subsets and hepatofibrosis in patients with chronic hepatitis B," Bulletin of Hunan Medical University, vol. 25, no. 3, pp. 248-250, 2000.

[9] H. W. E. Zhang, Z. X. I. Lin, Y. S. T. Tung et al., "Cordyceps sinensis (a traditional Chinese medicine) for treating chronic kidney disease," The Cochrane Database of Systematic Reviews, no. 12, Article ID CD008353, 2014.

[10] T. Hong, M. Zhang, and J. Fan, "Cordyceps sinensis (a traditional Chinese medicine) for kidney transplant recipients," The Cochrane Database of Systematic Reviews, vol. 12, no. 10, Article ID CD009698, 2015.

[11] N.-Q. Wang, L.-D. Jiang, X.-M. Zhang, and Z.-X. Li, "Effect of Dongchong Xiacao capsule on airway inflammation of asthmatic patients," Zhongguo Zhong Yao Za Zhi, vol. 32, no. 15, pp. 1566-1568, 2007.

[12] E. L. Y. Wong, R. Y. T. Sung, T. F. Leung et al., "Randomized, double-blind, placebo-controlled trial of herbal therapy for children with asthma," Journal of Alternative and Complementary Medicine, vol. 15, no. 10, pp. 1091-1097, 2009.

[13] Z. Kai, L. Yongjian, G. Sheng, and L. Yu, "Effect of Dongchongxiacao (Cordyceps) therapy on contrast-induced nephropathy in patients with type 2 diabetes and renal insufficiency undergoing coronary angiography," Journal of traditional Chinese Medicine, vol. 35, no. 4, pp. 422-427, 2015. 
[14] J.-Y. Guo, C.-C. Han, and Y.-M. Liu, "A contemporary treatment approach to both diabetes and depression by Cordyceps sinensis, rich in vanadium," Evidence-Based Complementary and Alternative Medicine, vol. 7, no. 3, pp. 387-389, 2010.

[15] Y. Xiong, S. Zhang, L. Xu et al., "Suppression of T-cell activation in vitro and in vivo by cordycepin from Cordyceps militaris," The Journal of Surgical Research, vol. 185, no. 2, pp. 912-922, 2013.

[16] T. Nakamura, T. Kushida, N. Okamoto et al., "Induction of autoimmune arthritis after direct injection of bone marrow cells from arthritis-prone SKG/Jcl mice into bone cavity of normal mice," Biological \& Pharmaceutical Bulletin, vol. 37, no. 11, pp. 1719-1726, 2014.

[17] S. S. Joo, D. I. Lee, and K. W. Hwang, "Inhibition of cytokineinduced $\beta$ cell apoptosis via laccase and its therapeutic advantages for insulin-dependent diabetes mellitus, type 1 diabetes," Biological \& Pharmaceutical Bulletin, vol. 33, no. 11, pp. 18541860, 2010.

[18] S. Tanaka, T. Hirano, T. Saito, N. Wakata, and K. Oka, "Pglycoprotein function in peripheral blood mononuclear cells of myasthenia gravis patients treated with tacrolimus," Biological and Pharmaceutical Bulletin, vol. 30, no. 2, pp. 291-296, 2007.

[19] M. Bagnasco, D. Venuti, I. Prigione, G. C. Torre, S. Ferrini, and G. W. Canonica, 'Graves' disease: phenotypic and functional analysis at the clonal level of the T-cell repertoire in peripheral blood and in thyroid," Clinical Immunology and Immunopathology, vol. 47, no. 2, pp. 230-239, 1988.

[20] M. I. Covas, A. Esquerda, A. García-Rico, and N. Mahy, "Peripheral blood T-lymphocyte subsets in autoimmune thyroid disease," Journal of Investigational Allergology \& Clinical Immunology, vol. 2, no. 3, pp. 131-135, 1992.

[21] A. Martin, N. K. Goldsmith, E. W. Friedman, A. E. Schwartz, T. F. Davies, and S. H. Roman, "Intrathyroidal accumulation of T cell phenotypes in autoimmune thyroid disease," Autoimmunity, vol. 6, no. 4, pp. 269-281, 1990.

[22] I. Ben-Skowronek, J. Sierocinska-Sawa, L. Szewczyk, and E. Korobowicz, "Interaction of lymphocytes and thyrocytes in graves' disease and nonautoimmune thyroid diseases in immunohistochemical and ultrastructural investigations," Hormone Research, vol. 71, no. 6, pp. 350-358, 2009.

[23] I. Ben-Skowronek, L. Szewczyk, B. Kulik-Rechberger, and E. Korobowicz, "The differences in T and B cell subsets in thyroid of children with Graves' disease and Hashimoto's thyroiditis," World Journal of Pediatrics, vol. 9, no. 3, pp. 245-250, 2013.

[24] H.-C. Lo, C. Hsieh, F.-Y. Lin, and T.-H. Hsu, "A systematic review of the mysterious caterpillar fungus Ophiocordyceps sinensis in Dong-ChongXiaCao (Dong Chong Xia Cao) and related bioactive ingredients," Journal of Traditional and Complementary Medicine, vol. 3, no. 1, pp. 16-32, 2013.

[25] X.-W. Zhou, L.-J. Li, and E.-W. Tian, "Advances in research of the artificial cultivation of Ophiocordyceps sinensis in China," Critical Reviews in Biotechnology, vol. 34, no. 3, pp. 233-243, 2014.

[26] Z. Liu, P. Li, D. Zhao, H. Tang, and J. Guo, "Anti-inflammation effects of cordyceps sinensis mycelium in focal cerebral ischemic injury rats," Inflammation, vol. 34, no. 6, pp. 639-644, 2011.

[27] X. Chen, B. May, Y. M. Di et al., "Oral Chinese herbal medicine combined with pharmacotherapy for stable COPD: a systematic review of effect on BODE index and six minute walk test," PLoS ONE, vol. 9, no. 3, Article ID e91830, 2014.

[28] N. Ishikawa, K. Eguchi, T. Otsubo et al., "Reduction in the suppressor-inducer $\mathrm{T}$ cell subset and increase in the helper $\mathrm{T}$ cell subset in thyroid tissue from patients with Graves' disease," The Journal of Clinical Endocrinology \& Metabolism, vol. 65, no. 1, pp. 17-23, 1987.

[29] M. Takaishi, K. Kobuke, M. Akiyama, H. Hara, and M. Yamakido, "Analysis of cellular immunity in patients with Graves' disease," Hiroshima Journal of Medical Sciences, vol. 39, no. 4, pp. 109-113, 1990.

[30] G. Aust, I. Lehmann, and H.-J. Heberling, "Different immunophenotype and autoantibody production by peripheral blood and thyroid-derived lymphocytes in patients with Graves' disease," Experimental and Clinical Endocrinology \& Diabetes, vol. 104, no. 1, pp. 50-58, 1996.

[31] M. Itoh, K. Uchimura, N. Hayakawa et al., "Surface expression and release of soluble forms of CD8 and CD23 in CD40- and IL-4-activated mononuclear cells from patients with Graves' disease (GD)," Clinical and Experimental Immunology, vol. 113, no. 2, pp. 309-314, 1998.

[32] G. Radetti, "Clinical aspects of Hashimoto's thyroiditis," Endocrine Development, vol. 26, pp. 158-170, 2014.

[33] S. Yu, Y. Fang, T. Sharav, G. C. Sharp, and H. Braley-Mullen, " $\mathrm{CD}^{+} \mathrm{T}$ cells induce thyroid epithelial cell hyperplasia and fibrosis," The Journal of Immunology, vol. 186, no. 4, pp. 26552662, 2011.

[34] M. Okajima, T. Wada, M. Nishida et al., "Analysis of T cell receptor $\mathrm{V} \beta$ diversity in peripheral $\mathrm{CD}^{+}$and $\mathrm{CD} 8^{+} \mathrm{T}$ lymphocytes in patients with autoimmune thyroid diseases," Clinical and Experimental Immunology, vol. 155, no. 2, pp. 166-172, 2009.

[35] H. S. Lee and J. S. Hwang, “The natural course of Hashimoto's thyroiditis in children and adolescents," Journal of Pediatric Endocrinology and Metabolism, vol. 27, no. 9-10, pp. 807-812, 2014.

[36] Z.-Y. Zhu, J. Chen, C.-L. Si et al., "Immunomodulatory effect of polysaccharides from submerged cultured Cordyceps gunnii," Pharmaceutical Biology, vol. 50, no. 9, pp. 1103-1110, 2012.

[37] J. Tang, D. Tian, and G. Liu, "Immunosuppressive effect of cordyceps CS-4 on human monocyte-derived dendritic cells in vitro," The American Journal of Chinese Medicine, vol. 38, no. 5, pp. 961-972, 2010. 


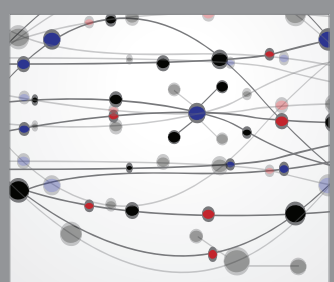

The Scientific World Journal
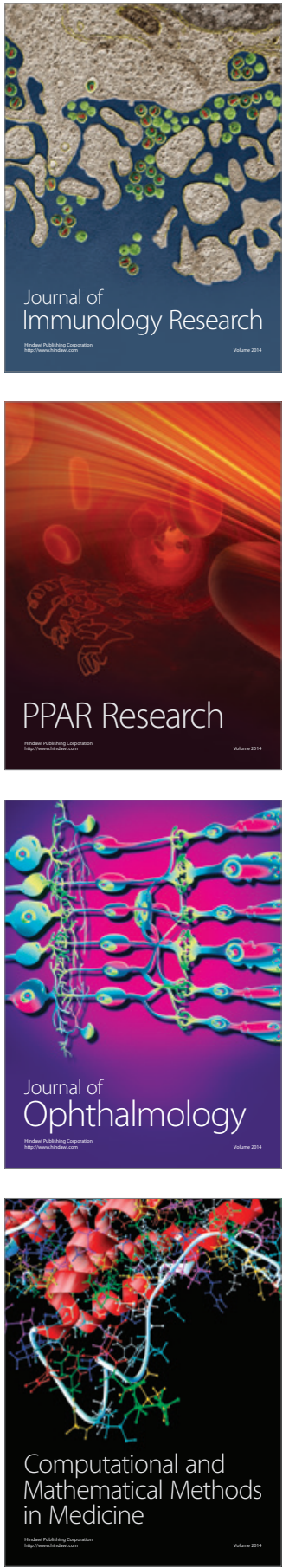

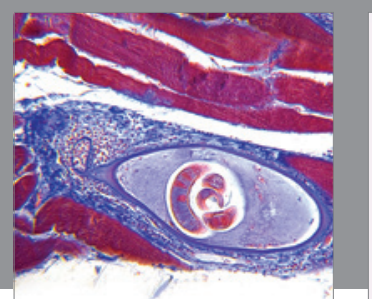

Gastroenterology Research and Practice

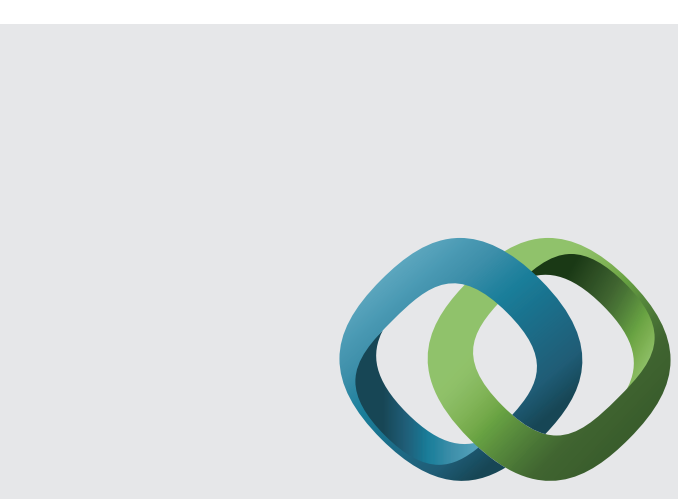

\section{Hindawi}

Submit your manuscripts at

http://www.hindawi.com
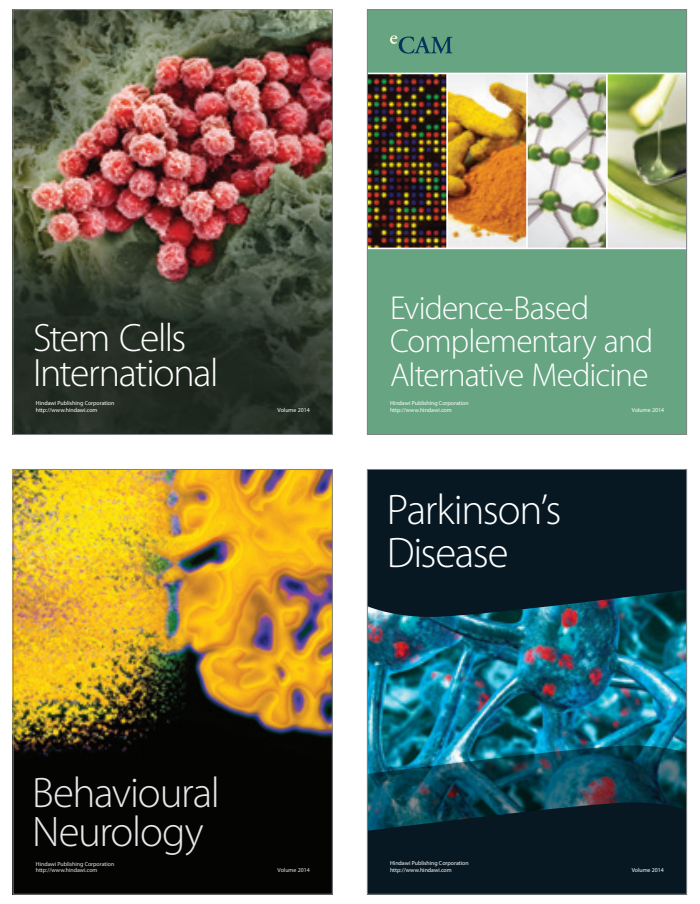
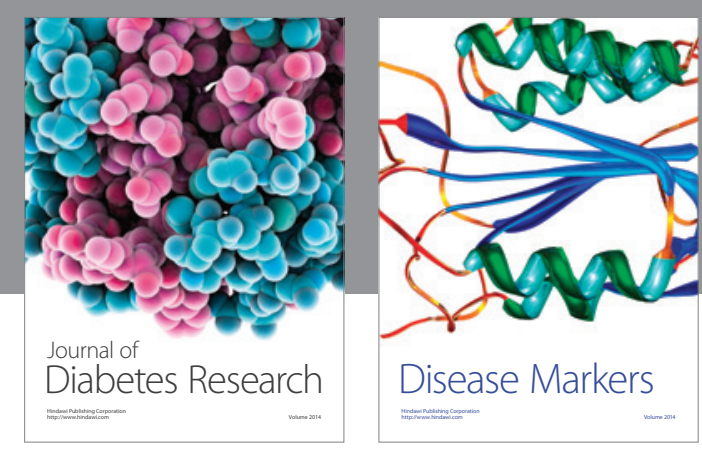

Disease Markers
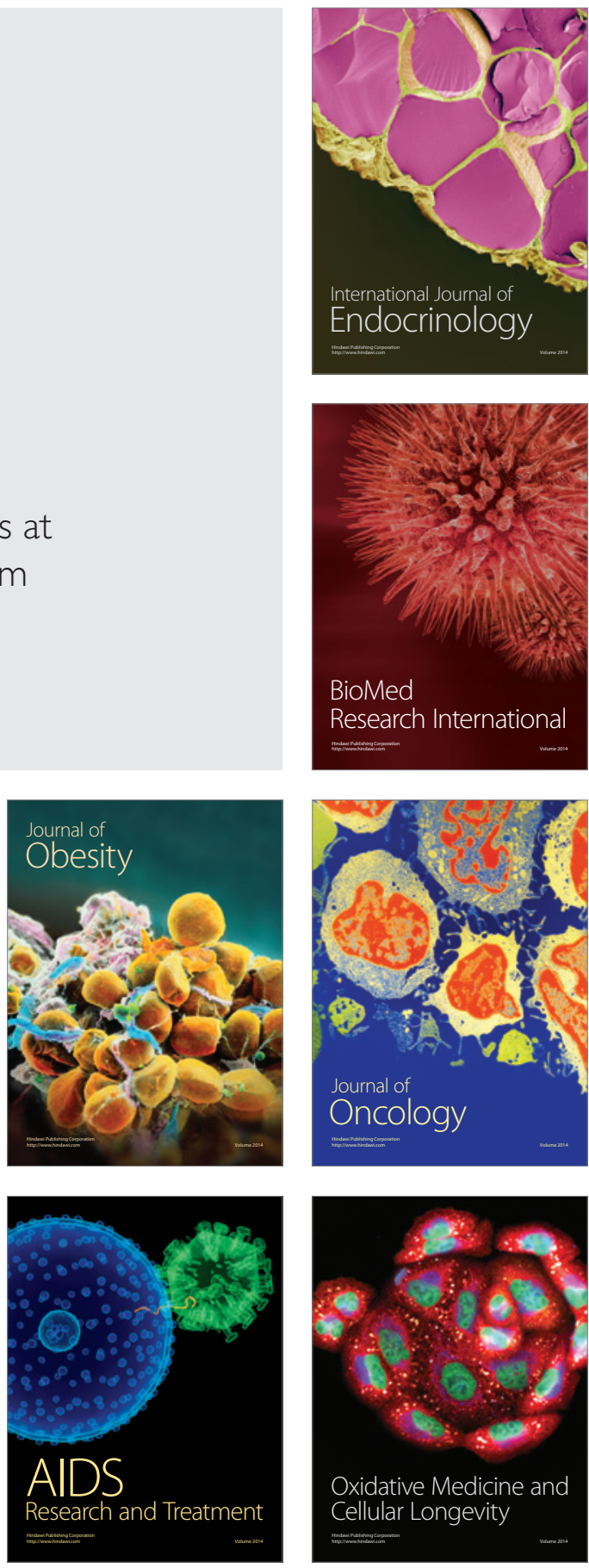